The Version of Record of this manuscript has been published and is available in the Canadian

Journal of Philosophy (2/27/2019) at

http:///www.tandfonline.com/10.1080/00455091.2019.1584935

\title{
PUBLIC REASON, NON-PUBLIC REASONS, AND THE ACCESSIBILITY REQUIREMENT
}

\section{JASON TYNDAL}

\begin{abstract}
In Liberalism without Perfection, Jonathan Quong develops what is perhaps the most comprehensive defense of the consensus model of public reason - a model which incorporates both a public-reasons-only requirement and an accessibility requirement framed in terms of shared evaluative standards. While the consensus model arguably predominates amongst public reason liberals, it is criticized by convergence theorists who reject both the public-reasons-only requirement and the accessibility requirement. In this paper, I argue that while we have good reason to reject Quong's call for a public-reasons-only requirement, all public reason liberals should endorse at least some shared evaluative standards and, hence, an accessibility requirement.
\end{abstract}

Public reason liberals hold that if a coercive law is to have legitimate authority over citizens, then each citizen subject to the law must have sufficient reason to agree to the law. ${ }^{1}$ For public reason liberals, this is what it means to justify a law to a free and equal citizen. But there is a divide amongst public reason liberals regarding what sorts of reasons ought to be permitted to enter into this justification process. Those who endorse a consensus theory of public reason argue that only public (or "shared") reasons can serve to justify coercive laws. Public reasons are reasons that are not grounded in one's personal comprehensive moral, philosophical, or religious conceptions. They are the sort of reasons that, ideally, anyone could agree to regardless of one's personal comprehensive doctrines. Those who endorse a convergence theory of public reason argue that non-public reasons should also have a place in the justificatory process despite the fact that such reasons are grounded in one's personal comprehensive doctrines and, as such, may not be shared by one's fellow citizens. The debate between consensus and convergence theorists within public reason liberalism is an important one. For if the consensus view is correct, and only

\footnotetext{
${ }^{1}$ Different theorists propose different sorts of caveats on this, some of which will be discussed below.
} 
public reasons can underwrite the justification of a coercive law, then this insight generates a significant moral constraint on the sorts of reasons citizens may invoke when advocating for a coercive law or even simply agreeing to such a law. This constraint is moral in nature since, according to one influential argument, advocating for or agreeing to coercive laws solely on the basis of non-public reasons constitutes a failure to respect one's fellow citizens as free and equal.

In this paper I defend a soft convergence model of public reason. Like other convergence models of public reason, the soft convergence model rejects the claim that only public reasons carry justificatory weight when considering whether a coercive policy or law is publicly justified. However, unlike other convergence models of public reason, the soft convergence model incorporates an accessibility requirement, one which dictates that for a reason to qualify as justificatory, it must satisfy at least some shared (agent-neutral) evaluative standards (specifically, shared standards of inference and shared standards of evidence). Given that consensus models of public reason incorporate both a public-reasons-only requirement and an accessibility requirement, the soft convergence model is best understood as occupying a viable middle ground between standard consensus and standard convergence models of public reason.

I begin in $\S 1$ by briefly clarifying the distinction between consensus and convergence models of public reason so as to highlight the central point of disagreement between the two models. In $\S 2$ and $\S 3$, I argue against the claim that a public-reasons-only restriction should be appended to a requirement of public justification. In $\S 2$, I take as my focal point Jonathan Quong's recent defense of the consensus model in which it is argued that public reason liberalism must incorporate a public-reasons-only restriction because it must incorporate a 
sincerity requirement. ${ }^{2}$ I contend that even if it is the case that public reason liberalism must incorporate some form of a sincerity requirement, it does not follow that such a requirement is robust enough to ground a public-reasons-only restriction. ${ }^{3}$ In $\S 3$, I argue that some consensus theorists have been prone to morally conflating the political practices of agreeing to a policy, proposing (or advocating for) a policy, and demanding that others adhere to a policy. This conflation may help to explain why some public reason liberals reach for a public-reasons-only restriction. In $\S 4$, I look to demarcate the soft convergence model of public reason from alternative convergence models by motivating the adoption of an accessibility requirement. On my view, public reason liberals should accept that there are at least some shared evaluative standards (namely, standards of inference and evidence). If this is right, then convergence theorists should favor some version of an accessibility requirement in place of other recentlyproposed alternatives, such as the less-restrictive intelligibility requirement.

One important qualification regarding the breadth of the ensuing claims is in order. My focus is on citizens who are not official agents of the state. Moreover, the particular question that I grapple with is this: do citizens fail to respect each other when they merely advocate for or agree to coercive laws on the basis of non-public reasons that others may not be able to accept? This is important since one might maintain that the obligations of officials diverge in some

\footnotetext{
${ }^{2}$ Micah Schwartzman is another leading defender of a principle of sincerity. Schwartzman, however, explicitly assumes that public justification requires public reasons and points readers to Quong's arguments for a preliminary defense of that assumption (2011, pp. 378, 386 fn. 33).

${ }^{3}$ As discussed in $§ 2$, Quong's advocacy for a public-reasons-only (PRO) restriction is ultimately based on an argument from respect for persons. However, other consensus theorists have argued for a PRO restriction on different grounds. Perhaps the most popular alternative approach is to attempt to ground a PRO restriction in concerns for stability or harmony. Eberle (2002, pp. 152-186) provides an admirable account of the challenges faced by such an approach. See Weithman (2010) and Hadfield and Macedo (2012) for recent developments of the approach along with related criticisms advanced by Thrasher and Vallier (2015), Kogelmann and Stich (2016), Billingham (2016), and Pallikkathayil (2017).
} 
respects from the obligations of citizens. I will elaborate further on this qualification in the concluding remarks.

$1 \quad$ Framing the Debate

It is the endorsement of a requirement of public justification that most clearly demarcates public reason liberalism from other versions of liberalism. While the precise demands of a requirement of public justification will vary from one public reason liberal to another, a generic requirement of public justification roughly states that a coercive law is justified only when each individual subject to the law has sufficient reason to agree to the law. ${ }^{4}$

The debate between consensus and convergence theories of public reason is a debate about what sorts of reasons can enter into the justificatory domain. Consensus models of public reason endorse a public-reasons-only (PRO) requirement, while convergence models of public reason reject the PRO requirement. Public reasons are often described as "shared" reasons: they are not grounded in one's personal comprehensive moral, philosophical, or religious conceptions, but are instead acceptable to all no matter what personal comprehensive doctrines one endorses. ${ }^{5}$

\footnotetext{
${ }^{4}$ This formulation is intentionally broad and underdeveloped in order to take account of the fact that public reason liberals of various stripes qualify the constituent elements of such a requirement in various ways. For example, for Rawls, only constitutional essentials and other matters of basic justice would fall within the scope of a requirement of public justification (1996, p. 137). Moreover, while Rawls expects these instruments to be justified only to rational individuals, other theorists may idealize members of the public in alternative ways. My intention is not to engage in these related debates here, but only to make a claim about what types of reasons should be permitted to count as justificatory reasons whatever one's view is regarding how individual members of the public should be idealized (if at all) or what sorts of coercive instruments should fall within the scope of such a requirement. For other generic formulations of such a requirement see Gaus (2010, p. 21), Vallier (2014, p. 24), and Pallikkathayil (2017, p. 413).

${ }^{5}$ Public reason is the view that the rules and principles that govern our social and political life are to be rationally justifiable (on the basis of reasons) to all citizens subjected to them. Of course, what it means for social and political principles to be rationally justifiable to all needs explanation. While some accounts of public reason incorporate the notion of "public" or "shared" reasons, public reason (the view) does not require that reasons be "public." As such, one might defend an account of public reason without appeal to "public" reasons or, at any rate, without an
} 
I will refer to reasons based in one's personal comprehensive doctrines as non-public reasons. These reasons are not necessarily private, since others may in fact accept them. Yet, non-public reasons do not transcend all comprehensive doctrines, hence they should not be considered public. To adopt the PRO requirement - as consensus theorists do - is to hold that only public reasons may ground an individual's acceptance or endorsement of some proposed coercive law.

Importantly, the convergence model does not require that for a law to be publicly justified that all citizens must agree to the law on the basis of non-public reasons. To the contrary, convergence models merely allow for citizens to agree to or endorse laws on the basis of non-public reasons, but they may certainly also agree to or endorse them on the basis of public reasons.

I have provided here only a coarse-grained distinction between consensus and convergence models of public reason. As I have remarked, there are some other differences, but they are not crucial to drawing the distinction at hand. For example, consensus theorists adopt an accessibility requirement along with the PRO requirement while convergence theorists have thus far rejected both. But, as I will argue below, while there is good reason to abandon the PRO restriction, convergence theorists should retain the accessibility requirement.

\section{Against the Public-Reasons-Only (PRO) Restriction}

If the debate between consensus and convergence theorists is primarily a debate about whether public reason liberalism should incorporate a PRO restriction, then one needs to take a stance on this issue prior to developing one's more nuanced and particular version of either the consensus

exclusive appeal to public reasons (Cf. Freeman 2007, p. 385). That is, public reason with non-public reasons remains a possibility. 
or convergence model. Since Jonathan Quong has recently constructed what is arguably the most sustained and complete defense of the consensus model, I will take as my focus his argument in favor of the PRO restriction. Given that the PRO restriction supplements a requirement of public justification, my aim is to defend the convergence model by arguing that Quong's case for such supplementation is unconvincing.

Quong argues that public reason liberalism must incorporate a sincerity requirement (2011, p. 265). The sincerity requirement dictates that "[w]e should sincerely think that our view of the [political] matter is based on political values everyone can be reasonably expected to endorse" (Rawls 1996, 241). Quong understands this to mean that we cannot "merely aim at getting others to assent to our proposal, we must sincerely believe our proposal can be justified to them" (2011, p. 265). This prompts Quong to construct the following principle of sincerity: A principle of justificatory sincerity (PJS) requires that A may only endorse $\mathrm{X}$ if the following are true (and vice versa for B):

1. A reasonably believes he is justified in endorsing $\mathrm{X}$.

2. A reasonably believes that $\mathrm{B}$ is justified in endorsing $\mathrm{X}$

Furthermore, following Rawls' s duty of civility,

3. A may only (in the political domain) offer arguments in favour of X to B that he reasonably believes B would be justified in accepting. (p. 266)

Quong asserts that PJS “undermines the convergence view of public reason” (2011, p. 266). His critical move is to argue that the only way we can sincerely believe others are justified in endorsing our proposals is if those proposals are grounded solely in public reasons. As such, it is condition two in particular that summons the PRO restriction (pp. 266-267). The general assertion, then, is that public reason liberalism must incorporate a PRO restriction because it must incorporate a sincerity requirement. Given this, two strategies are immediately available to dissenters. First, one might argue that a sincerity requirement is not a requirement of public 
reason liberalism, thus a PRO restriction cannot be appealed to on such grounds. Second, one might argue that even if some form of a sincerity requirement is necessary, such a requirement does not call for a PRO restriction. It is this second approach that I will adopt.

Quong maintains that the sincerity requirement has two important functions. First, it "helps to distinguish public reason from rhetoric and manipulation." Second, "it is also important due to the role it plays in sustaining... the value of civic friendship or respect." For A to be in a state of civic friendship with B is for A and B to respect "each other as free and equal citizens" (Quong 2011, p. 265). On Quong's account, then, a principle of sincerity - a principle that is satisfied only when we sincerely believe that others can accept the (public) reasons we offer in favor of our preferred positions - is necessary to respecting each other as free and equal citizens and, hence, is necessary for civic friendship (pp. 265-266).

I maintain that Quong's position is too strong. Offering public reasons is not a necessary condition of respecting each other as free and equal citizens. While it may be true that satisfying Quong's principle (the second condition in particular) - and hence only offering public reasons will increase the probability that public deliberation furnishes agreement (call this this practical claim), Quong thinks the claim that ultimately undercuts the convergence model is a moral claim. He believes that offering non-public reasons constitutes a failure to respect one's fellow citizens as free and equal. The idea is this: A fails to respect B as free and equal when $\mathrm{A}$ argues on behalf of $p$ and it is the case that $\mathrm{A}$ is not in the epistemic position to sincerely believe that $\mathrm{B}$ can accept the reason(s) in favor of $p$ that he or she offers to B. But, according to Quong, A cannot be in the epistemic position to sincerely believe that B can accept the reason(s) in favor of $p$ unless those reasons are public (Quong 2011, p. 267). Quong, however, does not adequately explain how a failure to be in such an epistemic position has the significant moral consequences 
that he attributes to it. A is not coercing B. A is not even demanding that B act in accordance with A's proposal. Rather, A, as a free and equal being herself, is merely presenting an argument for why she thinks a proposal should be accepted. In other words, she is simply expressing the very considerations that shape her own agency. It remains unclear why such an act should be construed as an instance of A failing to respect B as a free and equal citizen. ${ }^{6}$

On the face of it, it appears that consensus theorists have traditionally run together two different political practices that should be carefully delineated: (1) the practice of A proposing a policy to B; and (2) the practice of A demanding that B adhere to some policy. As Nicholas Wolterstorff has noted, the public reason liberal may think that "to advocate for some proposed piece of legislation is thus, implicitly if not explicitly, to place a moral demand on one's fellow citizens" (2012, p. 60). If the consensus theorist does intend to deny that there is any morallyrelevant difference between proposing a policy and demanding that others adhere to it, then we need a less-puzzling account of how A's proposing a policy to B amounts to A's demanding that B adhere to that policy.

What is perhaps morally problematic about a case of one person, Ari, demanding that another, Sky, adhere to some policy (without consideration for whether Sky has a sufficient reason, even counterfactually, to agree to that policy) is that Ari does not care that Sky is, to borrow a phrase from Thomas Scanlon, “a locus of reasons" (1998, p. 105) - he merely wants to claim authority over her agency. This, then, is an instance in which it might plausibly be argued that Ari fails to respect Sky as a free and equal citizen. ${ }^{7}$ But no such degree of disrespect occurs

\footnotetext{
${ }^{6}$ I will set aside momentarily worries about manipulation, but will address that concern towards the end of this section.

${ }^{7}$ If the mere act of demanding falls short of an act of coercion unless the demand is backed by force or the threat of future harm, one might dispute the idea that an act of mere demanding constitutes a failure to treat another as free and equal. I shall nevertheless proceed as if there is at least something morally problematic with the practice. For if
} 
when Ari merely argues on behalf of a policy - i.e., when he elucidates the reason(s) he has to endorse some particular policy. ${ }^{8}$ To propose or advocate for a policy - even one in which others do not have sufficient reason to agree to - is neither to impinge on their free and equal status nor to fail to recognize them as a locus of reasons. When Ari advocates on behalf of a policy, he publicizes what he takes to be a worthwhile argument for the policy. Not only does this not amount to any sort of obstruction of agency, but it has the virtue of bringing into the public Ari's genuine (we suppose) feelings about the matter. As Brian Carey argues, the admission of nonpublic reason into public debate may actually increase participation in public deliberation and “yield more stable agreements" (Carey 2018, p. 52). ${ }^{9}$

It should be emphasized that public reason liberals, in recognizing citizens to be free and equal, argue that citizens have defeater power. Citizens are free insofar as they are not naturally subject to the authority of others; and they are equal to one another with regard to their free status (Quong 2013; Gaus 2007, p. 90). As such, if a citizen does not have sufficient reason even counterfactually - to endorse some proposal, then absent the citizen's consent, the proposal is defeated. ${ }^{10}$ In light of this, when I propose reasons, even those grounded in personal comprehensive doctrines, I am not engaged in any sort of moral imposition. The structure of a requirement of public justification protects against such an imposition. In acknowledging that

the offering of non-public reasons does not amount to demanding - much less coercion - then the claim that offering non-public reasons is morally problematic appears implausible.

${ }^{8}$ Such an act may even encourage B to reflect upon his or her own reasons.

${ }^{9}$ Kogelmann and Stich (2016) also argue that permitting citizens to appeal to non-public reasons may promote stability.

${ }^{10}$ We must be careful not to construe a requirement of public justification as requiring both unanimous and actual consent. Public reason liberals drop the actual consent requirement in favor of the unanimity requirement, though they certainly disagree regarding the scope of such a requirement (i.e., should it apply only at the constitutional level, or apply to everyday laws as well?). Public reason liberals typically invoke the unanimity requirement when noting that coercive laws (or at least a certain subset of them) must be "endorsed by the reasons of all" (Gaus 2011, pp. xv-xvi; Cf. Rawls 1996, p. 137). 
each of my fellow citizens is free and equal and a locus of reasons, I recognize that they have defeater power. If this is right, then it makes sense to argue from personal comprehensive doctrines when one is unsure about how widespread his or her comprehensive views are. After all, sharing one's arguments may benefit the political process when either (1) those sharing similar comprehensive views realize that they have good reasons to support a particular proposal; or (2) one's arguments based on comprehensive views are shown to be poorly constructed. ${ }^{11}$ Still, the consensus theorist's emphasis on sincerity has its place. Let us suppose that Ari is advocating for $p$. Suppose further that, when confronted with Sky's skepticism, Ari argues that Sky's existing beliefs, when coupled with one or more essential inferences, commits Sky to endorsing $p$. But now imagine that Sky's beliefs are poorly-formed and the inferences that Sky would need to make are invalid inferences. Suppose further that Ari recognizes all of this, and thus recognizes that Sky does not have sufficient reason to endorse $p$, but nevertheless continues to press his line of reasoning to Sky. This sort of case captures the consensus theorist's worries about manipulation. Ari is not treating Sky as a locus of reasons. Rather, Ari merely views Sky as someone to be persuaded by any means necessary. Although this case captures genuine normative concerns regarding the role of sincerity, cases of this type cannot ground the sort of robust sincerity requirement that Quong is after for they cannot ground a PRO restriction. Manipulation is not a practice that is uniquely (or even necessarily) tied to non-public reasons. ${ }^{12}$ As such, an anti-manipulation requirement does not call for a PRO restriction. Once more, then,

\footnotetext{
11 (1) is the result of what Gaus calls "the division of epistemic labor" (2010 p. 26). The idea is that Sara may justify $p$ to Jack on the basis of religious reasons, while Sal justifies $p$ to Becky on the basis of considerations found, for example, in the writings of Kant. Others may appeal to religious reasons that are different than those offered by Sara, while yet others may appeal to the works of John Stuart Mill, James Madison, and so on. Gaus' point is that "many different reasons from many different perspectives may converge" together - the end result of a division of epistemic labor - in order to justify $p$ (2010, p. 26).

${ }^{12}$ Moreover, it is doubtful that any consensus theorist would say that any instance of Ari's offering of a non-public reason for consideration by Sky constitutes Ari's deliberate manipulation of Sky.
} 
the concern is that Quong has not adequately explained why one must be in the epistemic position of sincerely believing that others can accept $\mathrm{R}$ for $p$ in order to avoid failing to treat them as free and equal. If we set aside instances of deliberate manipulation, my not being in such an epistemic state plausibly provides me with a reason to publicize my argument - not to withhold it. ${ }^{13}$

While I do not deny that there may be a place in public reason liberalism for a requirement of sincerity, I claim that such a requirement is weaker than Quong contends. Importantly, such a requirement does not appear to implicate a PRO restriction. When arguing from comprehensive views, it is not evident that any moral harm is done so long as the relevant legislative proposal is not simply imposed on one's fellow citizens and so long as one is not resorting to mere manipulation.

I am not alone in denying that an individual necessarily fails to respect his fellow citizens when he advocates for a coercive law that he cannot sincerely believe all others have sufficient reason to endorse ${ }^{14}$ Christopher Eberle argues that it is a mistake to ground a doctrine of religious restraint (essentially a narrow version of the PRO restriction) in the claim that failure to adhere to such a doctrine amounts to a failure to respect others $(2009$, p. 152). According to Eberle, what is required of citizens and officials is that they adhere to the "ideal of conscientious

\footnotetext{
${ }^{13}$ To be sure, Rawls and other consensus theorists do provide space for citizens to express their genuine comprehensive beliefs. For example, Rawls' famous proviso says that we may "introduce into political discussion at any time our comprehensive doctrine, religious or nonreligious, provided that, in due course, we give properly public reason to support the principles and policies our comprehensive doctrine is said to support" (Rawls 1999, p. 144). It is unusual that the proviso is not objected to on the grounds that it allows for citizens to engage in insincere argumentation (as Quong would construe it). Perhaps it is the case that the "in due course" condition staves off such an objection. But it is not obvious that it should (from the perspective of consensus theorists that is). After all, if $\mathrm{P}$ does not have public reasons to offer at time $\mathrm{t}_{1}$, why think $\mathrm{P}$ can sincerely claim that he or she will have them at $\mathrm{t}_{2}$ (Audi 2011, p. 64)? If $\mathrm{P}$ has no reasonable grounds for believing that public reasons will become available, then Quong's argument, if it is right, would show that Rawls' proviso allows for citizens to disrespect one another in a way that consensus theorists want to eliminate.

${ }^{14}$ In addition to the following discussion of Eberle's position, see North (2012).
} 
engagement" - i.e., they should sincerely attempt to construct persuasive arguments in support of those coercive laws which they advocate for (2009, pp. 167-168).${ }^{15}$ Eberle believes that one needs an overly "thick" conception of what is required to show respect for others in order to claim that any citizen who is thoughtful and genuine in developing her arguments - even if those arguments rely solely on religious reasons - is guilty of failing to respect her fellow citizens (see Eberle's case of the Agapic Pacifist: 2009, pp. 152ff.). However, it does not appear that Eberle makes his case strictly in the context of a requirement of public justification. As such, he is not working under the assumption that each citizen has defeater power. In this respect, Eberle's argument is much more ambitious than mine. ${ }^{16}$ If one departs from a requirement of public justification (which incorporates a unanimity requirement) in favor of, for example, a simple majority rule, then new complications will indeed arise as a result of the rule's unique characteristics. ${ }^{17}$ Such complications may require reconsidering the case for a PRO requirement.

\section{Distinguishing Political Practices}

\footnotetext{
${ }^{15}$ We might add that the conscientious engager will acknowledge that the arguments which he or she finds reasonably persuasive may differ from the arguments which others find reasonably persuasive. I thank Eric Mack for this point.

${ }^{16}$ For a criticism of Eberle's argument, see Boettcher (2012, pp. 171ff).

${ }^{17}$ For example, within the context of a majoritarian system, the majority can limit the freedoms of certain minority groups (with some constitutional restrictions). These cases are especially problematic when the reasons offered by the majority are often rooted in comprehensive beliefs. Consider, for example, the same-sex marriage debate in the U.S, where some states have, in the past, put the issue to public vote. Within a majoritarian system, do those who support a ban on same-sex marriages disrespect (in a morally salient way) same-sex couples when it is known that same-sex couples cannot support such a law and, moreover, that such a law causes same-sex couples significant emotional distress? The case for answering in the positive has to be stronger within the context of the majoritarian system than it is in a system that endorses a public justification requirement. After all, in the former, the subjects to be coerced - same-sex couples - are at the mercy of the beliefs of the majority - who are not restricted from appealing to their comprehensive views - whether reasonable or not. But even here, a ban on non-public reasons serves as an ad hoc patch for the undesirable consequences of a majoritarian system.
} 
As explained in $\S 2$, a defense of a robust principle of sincerity may provoke consensus theorists to run together two different political practices: the practice of A demanding that B adhere to some policy and the practice of A proposing a policy to B. However, some public reasons liberals have also supposed that there is no morally-relevant difference between one agreeing to (or endorsing) a policy and one proposing (or advocating for) a policy. When this claim is united with the claim that there is no morally-relevant difference between proposing a policy and demanding that others adhere to that policy, it yields the corollary that there is no morallyrelevant difference between my agreeing to a policy and my demanding that others adhere to that policy. The consequence is that some public reason liberals have been prone to treat the practice of agreeing to a policy as morally on par with the practice of demanding that others adhere to that policy. For Rawls, this conflation begins with the claim that "the ideal of public reason does hold for citizens when they engage in political advocacy in the public forum... [and] holds equally for how citizens are to vote in elections when constitutional essentials and matters of basic justice are at stake” (Rawls 1996, p. 215). As Samuel Freeman has commented in discussing Rawls' view:

Public reason requires that when citizens vote in elections when matters of constitutional justice and basic justice are at stake, then, if they vote according to their comprehensive views, their vote must at least be compatible with the political values of public reason. There must be reasons of justice and political values of public reason that support their decision if they are to vote fairly and legitimately. Otherwise citizens violate the duty of civility. (Freeman 2007, p. 386)

On this view, to vote for a law that cannot be justified to others is to disrespect others. As such, the robust version of the principle of sincerity (and, hence, the PRO restriction) is said to hold even when merely selecting policies that will have jurisdiction over others. As Boettcher emphasizes, "liberal-democratic citizens also disrespect their compatriots when they attempt through voting or other advocacy in the public political forum to settle constitutional questions 
solely on the basis of religious doctrine" (2012, pp. 172-173). Our problem remains: it takes an exceedingly thick conception of what is required to show respect for others in order to claim that the act of registering one's genuine preferences necessarily entails disrespecting one's fellow citizens in some morally salient way. ${ }^{18}$ It is true, as Rawls remarked, that "[w]e recognize that our own [comprehensive] doctrine has, and can have, for people generally, no special claim on them beyond their own view of its merits" (Rawls 1996, p. 60). As such, perhaps I cannot demand that you accept $p$ on the basis of my comprehensive beliefs when you do not have sufficient reason to accept those beliefs. But it does not follow from this that I cannot agree to $p$ on the basis of such beliefs without disrespecting you.

When one morally conflates the political practices of agreeing, proposing, and demanding, it leads to some perplexing and unfortunate circumstances. For example, let us suppose that Sky agrees to $p$ on the basis of comprehensive reason $\mathrm{R}_{\mathrm{c}}$. Let us suppose further that a vote is taken to determine whether $p$ is publicly justified. According to the standard consensus approach, Sky fails to respect her fellow citizens as free and equal so long as she votes in favor of $p$ solely (or even substantially) on the basis of $\mathrm{R}_{\mathrm{c}}$. But notice the unusual implication that follows. The consensus theorist must say to Sky: "I know you agree to $p$, but I cannot let that stand. You must agree to $p$ for the reasons that I have deemed permissible." Assuming that $p$ is in fact agreed to by all citizens, the public reason liberal undercuts the public justification of $p$ by insisting that the PRO restriction applies to the political practice of agreeing to policies. If, as I have argued, the robust version of the principle of sincerity should be rejected in favor the weaker version, then the weaker version has no jurisdiction over the political practice of agreeing

\footnotetext{
${ }^{18}$ Within the public reason structure, voting serves as one way to determine whether a proposed law is in fact justified. I take A's voting in favor of $p$ to be an instance of A registering, through a political mechanism, her agreement with $p$.
} 
to policies. Instead, the principle of sincerity only applies in deliberative situations between two or more parties in which at least one party intentionally seeks to manipulate another. ${ }^{19}$

\section{$4 \quad$ Shared Evaluative Standards}

The PRO restriction is not the only restriction that consensus theorists place on citizens. In addition to the PRO restriction, consensus theorists also endorse an accessibility requirement which dictates that for a reason to qualify as justificatory, it must satisfy at least some shared (agent-neutral) evaluative standards. Evaluative standards are what Rawls referred to as "guidelines of inquiry" - the "principles of reasoning and rules of evidence..." (Rawls 1996, pp. 223-224). ${ }^{20}$ These are the principles and rules that one appeals to when determining (a) whether a reason supports a particular claim; and (b) whether the reason itself is well grounded.

Convergence theorists, such as Gerald Gaus and Kevin Vallier, reject both the accessibility requirement and the PRO restriction. However, a convergence theorist might endorse the accessibility requirement while rejecting the PRO restriction. Importantly, it is not the condition of requiring shared evaluative standards that limits justificatory reasons to public reasons. Some reasons may be public, but not satisfy the accessibility requirement. Alternatively, there may be non-public reasons that do satisfy the accessibility requirement. As such, the requirement of shared evaluative standards is independent of the PRO restriction.

But why think public reason liberalism needs an accessibility requirement? One worry is that if there are no shared standards of reasoning and evidence, then our judgments about

\footnotetext{
${ }^{19}$ Perhaps the scope of the principle would also cover cases in which A deliberately misrepresents his beliefs to B, yet (for whatever reason) does not intend to manipulate B.

${ }^{20}$ Freeman has framed Rawls' guidelines of inquiry as the "formal and procedural rules of argumentation and justification, including shared standards of evidence and reasoning (rules and standards of inference in deductive, inductive, and probabilistic reasoning, for example)" (Freeman 2007, p. 387).
} 
whether a reason qualifies as sufficient will be drastically and adversely impacted. Let us consider an example. Suppose that society S seeks to institute a law that prohibits littering in public places. But let us also suppose that citizen $\mathrm{C}$ rejects the law on the basis that he believes that littering (1) tends to improve property values; (2) is good for the environment; and (3) never poses a danger to individuals (no matter the substance of the litter). The crucial question is this: does $\mathrm{C}$ have a sufficient reason to reject the law (alternatively, does $\mathrm{C}$ possess a defeater that undermines the claim that $\mathrm{C}$ has a sufficient reason to accept the law)?

In normal circumstances, we might reasonably expect that those engaging $\mathrm{C}$ would call on him to provide evidence in support of his claims. We might also expect that those engaging $\mathrm{C}$ would require him to appeal to accepted standards of evidence. As such, if $\mathrm{C}$ were to say that his claims were based on mere intuitions, then we should not be surprised if his fellow citizens found his claims to be poorly supported. Assuming a good argument has been furnished on behalf of the law, and assuming that C's present claims are his only potential defeaters, then C's fellow citizens may continue to insist that $\mathrm{C}$ has a sufficient reason to agree to the law. Importantly, it is not the case that $\mathrm{C}$ must in fact agree to the law, but rather that (moderately) idealized $\mathrm{C}$ would find reason(s) to agree. It is arguably the case that acceptable levels of idealization would lead actual $\mathrm{C}$ to recognize that his claims rely on overly-weak standards of evidence.

If one rejects the accessibility requirement, then this sort of response to $\mathrm{C}$ is unacceptable since to reject the accessibility requirement is to reject the claim that standards of reasoning and evidence have some agent-neutral basis. ${ }^{21}$ But if such standards do not have an agent-neutral

\footnotetext{
${ }^{21}$ Some standards will arguably be society dependent (Tyndal 2016). I leave open the question of which, if any, standards could properly be construed as transcending societal norms, and hence be agent-neutral in a more robust sense.
} 
basis, then barring an explanation to the contrary, any criticism of C's standards is unwarranted. ${ }^{22}$ Consequently, one would have to say that $\mathrm{C}$ - even idealized $\mathrm{C}$ - does possess a defeater reason. If so, it would be morally wrong to impose the law in question on $\mathrm{C}$.

Identifying what the evaluative standards are is an additional and cumbersome challenge.

Freeman has suggested that

settled scientific theories with standards of evidence generally accepted by experts in their fields are admissible within public reason. When they are relevant, Rawls would then accept as admissible within public reason (for example) genetic theory, the theory of relativity, and neo-classical price theory in economics, and even neo-Darwinian theory of natural selection. The latter suggests that being shared by a majority of citizens generally is not a necessary feature of public reason (since Darwinism is not accepted by a majority in the U.S.); public reason thus can include some reasons that are not shared among citizens on the basis of their comprehensive views. (Freeman 2007, p. 387) ${ }^{23}$

For the consensus theorist, the accessibility requirement functions as a constraint mechanism alongside the PRO restriction. According to the standard consensus model, only reasons based on shared political values can enter into the pool of reasons that are potential justificatory reasons (hence the PRO restriction). However, as Rawls stresses, without guidelines of inquiry - i.e., without shared evaluative standards - "substantive principles cannot be applied" (Rawls 1996, p. 223). ${ }^{24}$

As for convergence theorists, whether one endorses or rejects the accessibility requirement has significant ramifications for one's account of public reason liberalism. Let us look at another example of what sorts of reasons could be appealed to on a convergence model if

\footnotetext{
${ }^{22}$ As elaborated below, one may have standing to criticize some of C's epistemic holdings on the basis of C's own evaluative standards.

${ }^{23}$ Freeman's last point is important. Though public reasons are often described as "shared," it is not the case that all public reasons will in fact be shared by all actual citizens. Even more, that $\mathrm{R}$ is in fact shared by all actual citizens is neither a necessary nor sufficient condition for that reason being considered "public."

${ }^{24}$ When deliberating about some particular law $\mathrm{L}$, the mere fact that a reason $\mathrm{R}$ is based on one or more shared political values does not necessarily make $\mathrm{R}$ a good or sufficient reason for $\mathrm{L}$.
} 
the accessibility requirement were rejected. Vallier is a convergence theorist who construes evaluative standards as agent-relative and hence rejects the notion of shared evaluative standards (2014, p. 107). This allows for divine revelation, for example, to be considered a legitimate evaluative standard. Even more, contradictory standards of divine revelation are said to be equally legitimate. So, the Christian's standard of divine revelation is as legitimate as the Muslim's standard. According to Vallier, it is permissible for "reasons supported by one of these agent-relative evaluative standards alone to figure into a public justification for a law" (2014, p. 107).

It does not follow from this that Vallier does not impose any sort of restriction whatsoever on the sorts of reasons that may be appealed to. To the contrary, he endorses an intelligibility requirement in which " $A$ 's reason $\mathrm{R}_{\mathrm{A}}$ can figure into a justification for (or rejection of) a coercive law $L$ only if it is intelligible to all members of the public" (Vallier 2014, p. 106). Moreover, "A's reason $\mathrm{R}_{\mathrm{A}}$ is intelligible for members of the public if and only if members of the public regard $\mathrm{R}_{\mathrm{A}}$ as epistemically justified for A according to A's evaluative standards" (Vallier 2014, p. 106). So, it is perfectly acceptable for the religious citizen to appeal to reasons based on divine revelation as long as those reasons are intelligible to all others in light of the religious citizen's acceptance of divine revelation.

Framed as such, the intelligibility requirement is ambiguous. On the one hand, one might reject the idea of shared standards of evidence, but endorse the notion of shared standards of inference. But if there are no shared standards of evidence, then even if one draws valid inferences, some positions that one reaches will clearly be unjustified. For example, on the approach under consideration, one does not criticize $\mathrm{P}$ for believing that a pack of unicorns has formed a colony on the summit of Mt. Everest. One only criticizes the way P makes inferences 
based on that belief. On the other hand, if all evaluative standards are to be seen as agentrelative, then different individuals can also have different standards of inference. On this approach, it would follow that S can criticize P's beliefs and inferences only if P has not adhered to his or her $o w n$ standards.

On the issue of whether Vallier endorses the weaker or the stronger of the two positions, the clearest passage we get is this:

[i]f I cannot see your purported reasons as reasons for you even according to your own evaluative standards, then I cannot reason from your standpoint by definition. That said, intelligibility might deny justificatory status to reasons based on poor inferences and bad information, as it requires that justificatory reasons possess epistemic justification. (Vallier 2014, p. 107).

But once again, are so-called "poor inferences" poor because they fail to meet some agent-neutral standard; or, are they poor because the appropriate agent-relative standard was improperly applied? If Vallier intends to endorse agent-neutral standards of inference, but agentrelative standards of evidence, then an argument needs to be offered for why the two types of evaluative standards can permit dissimilar evaluative criteria. Otherwise, it is plausibly the case that any argument in favor of agent-neutral standards of inference will undercut any claim to agent-relative standards of evidence. ${ }^{25}$ The worry, then, is that the intelligibility requirement is too weak; some comprehensive views may have to be deemed unjustified on the basis of agentneutral evaluative standards. ${ }^{26}$

\footnotetext{
${ }^{25}$ Vallier clarifies that the intelligibility requirement does not require shared evaluative standards (2014, p. 124). But this of course means that it could permit them. What makes Vallier's position unsettling is that he maintains that his view does not require any shared evaluative standards, yet he implies that, as a contingent matter, it will be the case that at least some standards are shared (particularly standards of inference). Yet, given the commitments of his view, it must be the case that if a citizen does not recognize, for example, the rule of modus ponens, then that citizen cannot be expected to reason in accordance with that rule.

${ }^{26}$ Quong argues that "[a]rguments and reasons may be intelligible without being justifiable, and thus merely seeing someone else's position as intelligible does not entail that one must see that other person's position as justifiable" (2011, p. 270 fn. 42).
} 
A rejection of the intelligibility requirement need not drive us to the consensus model.

This is partly because I doubt that the PRO restriction does any worthwhile work beyond the work that is already done by the accessibility requirement. After all, if one's comprehensive views meet shared standards of evidence and inference, then what is the point of further requiring that one's reasons be public? ${ }^{27}$ The consensus approach, then, appears to be too strong.

There is a viable middle ground to be defended, one that entails a rejection of the PRO restriction but an endorsement of shared standards of evidence and inference. As I have implied, an endorsement of shared evaluative standards is frequently associated with a notion of accessibility. While accessibility might be understood in a variety of ways, I take P's reason R to be accessible if and only if R (including P's rationale for R) is supported by shared evaluative standards (Cf. Vallier 2011a, p. 369; 2014, p. 108). Moreover, R must be accessible in order for it to play a justificatory role with regard to legislative proposals. This notion of accessibility will clearly restrict what sorts of reasons can count as justificatory reasons - reasons that can be appealed to in order to justify (or defeat) a particular proposal. ${ }^{28}$

The accessibility requirement is widely-discussed in the public reason literature.

Importantly, while it has traditionally been associated with consensus models of public reason, ${ }^{29}$

\footnotetext{
${ }^{27}$ The issue is further complicated if it is the case that we cannot clearly distinguish between comprehensive and non-comprehensive doctrines (for a discussion of this worry, see Gaus 2003b, p. 180ff.; also Gaus 2004). Perhaps, then, what we should be most concerned with is whether our reasons and arguments meet certain standards of evidence and inference.

${ }^{28}$ I assume, for now, that there is a symmetry between the epistemic standards that apply to the practice of agreeing to a proposal and the epistemic standards that apply to the practice of rejecting a proposal - namely, both practices are subject to the accessibility requirement. However, symmetry claims are controversial depending on which political practices are being compared. For example, Gaus and Vallier deny symmetry with respect to the practices of proposing a law and rejecting a proposed law (2009, p. 64). See Boettcher's criticism of the asymmetric convergence model (2015) and Vallier's reply (2016).

${ }^{29}$ Vallier, for example, characterizes models of public reason that incorporate an accessibility requirement as weak consensus models. Moreover, he explicitly states that one defining feature of convergence models is that they entail a rejection of any accessibility requirement (Vallier 2011b, p. 263).
} 
there is nothing that dictates that if one employs an accessibility requirement, then one must be a consensus theorist. One plausible explanation of why the accessibility requirement has typically been attached to consensus theories is that some consensus theorists may believe that the accessibility requirement would block all religious reasons from entering into public justification. As Vallier has noted, "the accessibility requirement was practically crafted with religious reasons in mind" (Vallier 2011a, p. 385). ${ }^{30}$ This has perhaps led some to think of the accessibility requirement as being necessarily linked to consensus theories. Vallier, for example, says that "[w]ithout accessibility, public reason will lean towards "convergence" conceptions of public reason..." (p. 389). But as I have stressed, the accessibility requirement can be incorporated into convergence models of public reason. I refer to such models as soft convergence models of public reason.

As I construe the term, accessibility incorporates the notion of adequacy. As Robert Audi writes, "[a]n adequate reason (for something) is one that, in rough terms, evidentially justifies the belief, act, or other element it supports. We might also say that adequacy implies that an action or belief based on the reason is thereby rational" (2011, pp. 67-68). Audi proceeds to say that an adequate reason must "be in a certain way accessible to rational adults: roughly, appraisable by them through using natural reason in the light of facts to which they have access on the basis of exercising their natural rational capacities" (2011, p. 70). In other words, adequate (or justificatory) reasons must pass agent-neutral evaluative criteria. I have described such criteria in terms of shared evaluative standards.

\footnotetext{
${ }^{30}$ It must be remembered, however, that religious reasons are not the only class of non-public reasons affected by a PRO restriction. Any reasons that are grounded in comprehensive doctrines - whether religious or not - are impacted by the PRO restriction.
} 
The consequences of not accepting at least a minimalist accessibility requirement are high: in the absence of such a requirement, defeater reasons will be radically unconstrained. For this reason, I take the issue about what degree of accessibility is most appropriate to be a fundamental aspect of the on-going debate not just between consensus and convergence theorists, but amongst convergence theorists.

Regarding the issue of defeaters, it is important to note that a justified reason is not a sufficient reason (and hence, not an undefeated reason). As such, even if a reason is accessible, it might well be defeated by a weightier accessible reason. ${ }^{31}$ So, the accessibility requirement merely places a constraint on which reasons may be considered justificatory reasons. To reemphasize, such reasons need not be available to actual agents, but only to their moderately idealized counterparts.

It might be objected that the view presented here is engaging in a bit of rhetoric by conveniently associating the accessibility requirement with rationality or reasonableness. This is a result of speaking about the accessibility requirement in terms of the notion of adequacy. When we deliberate about whether reason R evidentially justifies some belief or action, we are deliberating about whether R satisfies some evaluative standards - whatever those standards may be. There may be a temptation, then, to go further and label that which satisfies such standards as "reasonable" or "rational." This is not problematic so long as we avoid extracting our evaluative standards from antecedent assumptions about what is reasonable or rational. As such, I make no assumptions here as to what sorts of appeals would be ruled out by an accessibility requirement. For example, I do not assume that an accessibility requirement will constrain all religious

\footnotetext{
${ }^{31}$ It is of course the case that disagreement will arise regarding, for example, whether a reason $\mathrm{R}_{1}$ in fact defeats reason $\mathrm{R}_{2}$. As Audi notes, clearly articulating degrees of adequacy or justification is a complicated matter, but it is doubtful that any plausible political theory can dispense with the idea that there are varying degrees of adequate reasons (2011, p. 68).
} 
reasons. Nor do I assume that any religious reasons will be vindicated. ${ }^{32}$ Such issues must be the subject of on-going debates about whether such appeals are adequate to evidentially justify the claims, actions, or policies, they are intended to support. What is of crucial importance is that the accessibility requirement applies equally to religious reasons, and other non-public reasons, as well as public reasons. ${ }^{33}$ At the end of the day, what matters is whether our reasons (and the beliefs they are based on) are well-grounded. ${ }^{34}$

Part of settling debates about the role of religious reasons will require putting extensive effort into better clarifying and defining the notion of shared evaluative standards that is essential to the notion of accessibility. Viewed as such, the issue of how to best characterize the relationship between a sufficient reason and an individual member of the public is an issue that must draw from working theories of rationality. To gain traction on many of the outstanding issues in political philosophy (and ethics more generally), we must further confront the problem of how to best distinguishing between "good" and "bad" reasons." This is no easy task, but it is a problem that profoundly impacts the vast majority of ethical and political theories.

\footnotetext{
${ }^{32}$ Vallier argues that an accessibility requirement would vindicate at least some religious reasons. For example, he believes that an accessibility requirement would affirm an anti-abortionist argument that relies both on the existence of God as well as the idea that 'God gives each human body a soul that provides a human life with intrinsic worth' $(2014,114)$. However, while Vallier assumes such an argument will be epistemically justified, he says very little about what shared evaluative standards might be incorporated into an accessibility requirement. At times, Vallier appears to imply that if a belief is rationally grounded - i.e., it is grounded on some reason - then it qualifies as accessible. If this is the intended implication, it would ignore that an accessibility requirement may incorporate standards of evidence which govern belief formations. Until these standards are further clarified, it makes little sense to claim that belief in things like God-given souls will be vindicated by the accessibility requirement.

${ }^{33}$ As Eberle stresses, religious believers are understandably critical of "wholesale restrictions on the justificatory role of religion, even religion that is manifestly liberal. Such wholesale restrictions will inevitably be objectionably arbitrary, because some religious convictions are no different in any normatively relevant respect than some of the claims on which some morally necessary coercive laws rely" (2011, p. 292).

${ }^{34}$ James Boettcher remarks that "[i]f it turns out that some religious beliefs are accessible and ultimately separable from religious comprehensive doctrine, so be it. Religious premises would be to that extent permissibly included in political justifications" (2015, p. 200). Boettcher's position is a step in the right direction. However, unlike the view outlined here, Boettcher endorses a PRO restriction which makes it unlikely that many religious beliefs will qualify as justificatory reasons.
} 


\section{$5 \quad$ Concluding Remarks}

I have focused on the case of citizens who are not official agents of the state. Specifically, I am concerned with whether citizens fail to respect each other when they either agree to or advocate for coercive laws on the basis of reasons that others may not be able to accept. In doing so, I have adopted a particular form of pubic reason liberalism. To see this, let us distinguish between two modes of public reason. The first mode is what I will call top-down public reason. On this mode, "decisions regarding constitutional essentials and matters of basic justice should be decided by political authorities... (Freeman 2007, p. 329). In other words, it is up to public officials to determine which laws satisfy the requirement of public justification. This mode of public reason can be contrasted with bottom-up public reason, in which ordinary citizens express their preferences - e.g., through voting - in order to determine whether a proposed law satisfies the requirement of public justification. The difference between the two modes is important. On the top-down mode, public officials are the ones to decide whether individual citizens have sufficient reason to agree to a proposal. On the bottom-up mode, it is the citizens themselves (or perhaps we should say their suitably-idealized counterparts) that determine whether they have a sufficient reason to agree to a proposal.

It may well be the case that the epistemic or normative constraints that one places on the political practice of proposing a law will depend on which mode of public reason is under discussion. If public reason liberalism is meant to be nothing more than a decision procedure for public officials to follow - i.e., purely a matter of top-down public reason - then one might plausibly argue that public officials should be confined to speaking only in terms of public 
reasons (Freeman 2007, p. 386; Rawls 1996, p. 216). ${ }^{35}$ After all, perhaps the most practically expedient way to satisfy the requirement of public justification, as a public official, is to appeal only to political values that all citizens would accept. For if officials propose a law that can be justified only on the basis of comprehensive reasons, it is extremely likely that at least one citizen will have a different, but reasonable, comprehensive view which serves as grounds to reject the proposal. ${ }^{36}$ Importantly, I leave open the issue of whether an appeal to practical expediency could help to normatively justify a PRO restriction on a top-down account of public reason.

This qualification aside, I have argued against the claim that citizens fail to respect one another when they advocate for coercive laws on the basis of non-public (but genuine) reasons. Because of this, I have rejected the call for a public-reason-only restriction. However, I have maintained that public reason liberals should remain committed to an accessibility requirement that is framed in terms of shared (agent-neutral) evaluative standards. The resulting view occupies a viable middle ground between the consensus and convergence models of public reason that have recently been proposed..$^{37}$

\footnotetext{
${ }^{35}$ For a discussion of how the constraints on legislators might be seen as more (normatively) demanding than that of citizens, see Gaus (2010, p. 29ff) and North (2012, p 188ff.).

${ }^{36}$ An account of public reason liberalism need not incorporate only a single mode of public reason. But each mode evokes different challenges. For example, if public officials engaged in top-down public reason are to appeal only to political values that all would accept, then they must be able to specify what the relevant political values are in order to know what public reasons there are - and they must be able to do this without relying on any comprehensive doctrines. But this may prove to be an overly-difficult task. Alternatively, while on the bottom-up mode of public reason it is citizens, and not officials, who ultimately determine whether a law is publicly justified, it remains to be seen how one can square the practice of idealization (even moderate) with the practice of voting. Public reason liberals are generally concerned with the reasons that citizens can be said to have, not the reasons they actually have. But if voting is a means of registering one's actual preferences, it is difficult to see how we are to know that one's vote is based on one's moderately idealized reasons, and not one's shortcomings in reasoning.

${ }^{37}$ I would like to thank the editor and two anonymous referees at the Canadian Journal of Philosophy for their valuable feedback. I am also grateful Eric Mack and Gerald Gaus for their comments on an earlier version of this paper.
} 


\section{References}

Audi, Robert. (2011). Democratic Authority and the Separation of Church and State. New York, NY: Oxford University Press.

Billingham, Paul. (2016). "Convergence Justifications within Political Liberalism: A Defence." Res Publica 22, 2: 135-153.

Boettcher, James. (2012). "The Moral Status of Public Reason.” The Journal of Political Philosophy 20, 2: 156-177.

— (2015). “Against the Asymmetric Convergence Model of Public Justification.” Ethical Theory and Moral Practice 18, 1: 191-208.

Carey, Brian. (2018). "Public Reason - Honesty, Not Sincerity.” The Journal of Political Philosophy 26, 1: 47-64.

Eberle, Christopher. 2002. Religious Conviction in Liberal Politics. New York: Cambridge University Press.

— (2009). "Basic Human Worth and Religious Restraint." Philosophy \& Social Criticism 35, 12: $151-181$.

— (2011). “Consensus, Convergence, and Religiously Justified Coercion.” Public Affairs Quarterly 25, 4: 281-303.

Freeman, Samuel. (2007). Rawls. New York, NY: Routledge.

Gaus, Gerald. (2003). Contemporary Theories of Liberalism. Thousand Oaks, CA: SAGE Publications.

- (2004). "The Diversity of Comprehensive Liberalisms." In Handbook of Political Theory. Ed. Gerald F. Gaus and Chandran Kukathas. Thousand Oaks, CA: SAGE Publications.

- (2007). "On Justifying the Moral Rights of the Moderns: A Case of Old Wine in New Bottles." In Liberalism: Old and New. Ed. Ellen Frankel, Fred D. Miller, Jr., and Jeffrey Paul. New York, NY: Cambridge University Press.

— (2010). “The Place of Religious Belief in Public Reason Liberalism.” In Multiculturalism and Moral Conflict. Ed. Maria Dimova-Cookson and Peter M.R. Stirk. New York, NY: Routledge. 
— (2011). The Order of Public Reason. New York, NY: Cambridge University Press.

Gaus, Gerald and Vallier, Kevin. (2009). "The Roles of Religious Conviction in a Publicly Justified Polity." Philosophy \& Social Criticism 35, 1-2: 51-76.

Hadfield, Gillian and Macedo, Stephen. (2012). "Rational Reasonableness: Toward a Positive Theory of Public Reason. Law and Ethics of Human Rights 6, 1: 7-46.

Kogelmann, Brian and Stich, Stephen. (2016). "When Public Reason Fails Us: Convergence Discourse as Blood Oath. American Political Science Review 110, 3: 717-730.

North, Richard. (2012). "Public Reason, Religious Restraint and Respect.” Philosophia 40, 2: 179-193.

Pallikkathayil, Japa. (2017). "Resisting Rawlsian Political Liberalism.” Philosophy \& Public Affairs 45, 4: 413-426.

Quong, Jonathan. (2011). Liberalism without Perfection. New York, NY: Oxford University Press.

- (2013). "Public Reason." The Stanford Encyclopedia of Philosophy (Summer 2013 Edition), Edward N. Zalta (ed.), URL = <http://plato.stanford.edu/archives/sum2013/entries/public-reason/>.

Rawls, John. (1996). Political Liberalism. New York: Columbia University Press.

— (1999). “The Idea of Public Reason Revisited.” In The Law of Peoples. Cambridge, MA: Harvard University Press.

Scanlon, T.M. (1998). What We Owe to Each Other. Cambridge, MA: Belknap Press.

Schwartzman, Micah. (2011). "The Sincerity of Public Reason.” The Journal of Political Philosophy 19, 4: 375-398.

Thrasher, John and Vallier, Kevin. (2015). "The Fragility of Consensus: Public Reason, Diversity, and Stability. European Journal of Philosophy 23, 4: 933-954.

Tyndal, Jason. (2016). "Moderate Idealization and Information Acquisition Responsibilities." Res Publica 22, 4: 445-462.

Vallier, Kevin. (2011a). “Against Public Reason Liberalism's Accessibility Requirement.” Journal of Moral Philosophy 8,3: 366-389.

- (2011b). "Convergence and Consensus in Public Reason." Public Affairs Quarterly 25, 4: 261-280. 
— (2014). Liberal Politics and Public Faith. New York, NY: Routledge.

- (2016). "In Defense of the Asymmetric Convergence Model of Public Justification: A Reply to Boettcher." Ethical Theory and Moral Practice 19, 1: 255-266.

Weithman, Paul. (2010). Why Political Liberalism? New York, NY: Oxford University Press.

Wolterstorff, Nicholas. (2012). Understanding Liberal Democracy. Ed. Terence Cuneo. New York, NY: Oxford University Press. 